УДК 633.34:631.53.04

ПРОДУКТИВНОСТЬ СОИ В ЗАВИСИМОСТИ ОТ СПОСОБОВ И НОРМ ВЫСЕВА В УСЛОВИЯХ ЧУВАШСКОЙ РЕСПУБЛИКИ

\author{
Хадарова И.В., Филиппова С.В., Елисеева Л.В. \\ ФГБОУ ВО «Чувашский государственный аграрный университет», \\ Чебоксары, e-mail: ludmilaval@yandex.ru
}

\begin{abstract}
Было изучено влияние способов и норм высева на продуктивность сои. Анализ влияния изучаемых факторов проводили на основании следующих данных: полевая всхожесть и выживаемость, продолжительность вегетации, биометрические показатели растений, элементы продуктивности растений, урожайность. Набольшая полевая всхожесть наблюдалась в широкорядных посевах, а сохранность растений при посеве с междурядьями 45 см при нормах высева 450 и 600 тыс. шт/га. Было отмечено, что до начала цветения развитие растений в разных вариантах происходило одинаково, далее, в более загущенных посевах, процесс плодообразования и созревания несколько затянулся (на 5-7 дней в среднем). Более высокорослые растения сформировались при посеве семян с нормой 600 тыс. шт/га при широкорядном посеве. В среднем за два года наилучшие показатели продуктивности растений были получены при посеве с нормой высева 300 тыс. шт/га - количество бобов на растении и масса 1000 семян. 2019 г. оказался более благоприятным и продуктивным. При всех способах посева наблюдалось увеличение урожайности. В 2018 г. самым продуктивным оказался вариант с посевом с междурядьями 45 см и нормой высева 600 тыс. шт/га - 3,32 т/га, а также данная норма высева оказалась самой оптимальной при всех способах посева. В среднем за два года с увеличением нормы высева происходило увеличение урожайности при всех способах посева. Наименьшие различия между способами посева наблюдались при посеве с нормой высева 450 тыс. шт/га.
\end{abstract}

Ключевые слова: соя, способы посева, нормы высева, продуктивность

\title{
SOYBEAN PRODUCTIVITY DEPENDING ON METHODS AND SEEDING RATES IN THE CONDITIONS OF THE CHUVASH REPUBLIC
}

\author{
Khadarova I.V., Filippova S.V., Eliseeva L.V. \\ Chuvash State Agrarian University, Cheboksary, e-mail: ludmilaval@yandex.ru
}

\begin{abstract}
We have investigated the influence of methods and sowing rates on productivity of soybean. The analysis of the influence of the studied factors was carried out on the basis of the following data: field germination and survival, vegetation duration, biometric indicators of plants, elements of plant productivity, yield. Large field germination was observed in wide-row crops, and the safety of plants when sown with row spacing of $45 \mathrm{~cm}$ at seeding rates of 450 and 600 thousand units / ha. It was noted that before the beginning of flowering, the development of plants in different variants was the same, then in more thickened crops, the process of fruit formation and maturation was somewhat delayed (for 5-7 days on average). Taller plants were formed when sowing seeds with a rate of 600 thousand units / ha for wide-row sowing. On average, over two years, the best indicators of plant productivity were obtained when sowing with a seeding rate of 300 thousand units/ha - the number of beans per plant and the weight of 1000 seeds. 2019 turned out to be more favorable and productive. With all methods of sowing, there was an increase in yield. In 2018, the most productive option was a seeding with row spacing of $45 \mathrm{~cm}$ and a seeding rate of 600 thousand units / ha $-3.32 \mathrm{t} / \mathrm{ha}$, and this seeding rate was the most optimal for all seeding methods. On average, over two years, with an increase in the seeding rate, there was an increase in yield for all seeding methods. The smallest differences between seeding methods were observed when sowing with a seeding rate of 450 thousand units / ha.
\end{abstract}

Keywords: soy, seeding methods, seeding rates, productivity

Значение сои для мирового земледелия трудно переоценить. Эта культура имеет широкое использование в различных отраслях промышленности. Ее используют как пищевую, техническую и кормовую культуру. Посевные площади под соей ежегодно увеличиваются как в целом в мире, так и в нашей стране, что связано с растущими потребностями в зерне данной культуры [1]. Несмотря на то, что основные площади под соей находятся в Дальневосточном и Северо-Кавказском федеральных округах, культура продвигается на север, благ. ря скороспелым сортам, и является перспективной для Чувашской Республики. Увеличить валовой сбор в первую очередь необходимо за счет повышения урожайности, что достигается подбором агротехнических приемов, позволяющих реализовать в большей мере продуктивность сортов.

Продуктивность растений зависит от многих факторов, таких как почвенно-климатические условия, генетический потенциал сортов, их адаптивность к конкретным условиям, особенностей агротехники, качества семенного материала [2, 3]. Агротехника, применяемая при возделывании культуры, оказывает влияние на урожайность и качество зерна сои. Оптимизация параметров посева позволяет реализовать потенциал сортов [4]. 
Для формирования максимальной урожайности сортов необходима оптимальная плотность стеблестоя, то есть подбор способов посева и норм высева применительно к каждой культуре и сорту [5]. Ряд исследователей отмечает, что для обеспечения максимальной продуктивности и высокого качества семян следует применять широкорядные посевы [6] и повышенные нормы высева [7]. Однако также были получены данные, указывающие на то, что соя достаточно пластичное растение, и различные междурядья и нормы высева не оказывают существенного влияния на ее продуктивность [8]. Все это указывает на необходимость совершенствования технологии возделывания применительно к конкретному сорту и условиям вегетации.

Таким образом, для каждой природноклиматической зоны с целью увеличения продуктивности сои, следует подбирать оптимальные способы и нормы высева с учетом требований сорта [9].

Цель исследования: изучить влияние способов и норм высева на урожайность сои, выращиваемой на светло-серых лесных почвах Чувашской Республики.

\section{Материалы и методы исследования}

Исследования проводились в 2018 2019 гг. на опытном участке УНПЦ «Студенческий» ФГБОУ ВО «Чувашская ГСХА», который расположен в северной части республики. Почвы участка светло-серые лесные тяжелосуглинистые, характеризуются низким содержанием гумуса (до $2,5 \%$ ), повышенным содержанием фосфора $(14,6$ мг на 100 г) и средним - калия $(11,5$ мг на 100 г), слабокислые (pH 5,7). Объектом исследований служил раннеспелый сорт сои северного экотипа СибНИИК 315. Погодные условия в годы исследований отличались от средних многолетних. Так, 2018 г. характеризовался низкой температурой начала вегетации и высокими температурами с умеренным количеством осадков во второй половине вегетации. 2019 г., наоборот, в начале вегетации оказался достаточно теплым, а середина вегетации и вторая ее половина отличились изобилием осадков и температурой ниже средних многолетних показателей.

Посев сои проводился во второй декаде мая - 15 мая в 2018 г. и 14 мая в 2019 г., учетная площадь делянки - 3,2 $\mathrm{M}^{2}$, повторность шестикратная, расположение делянок систематическое. Способы посева в опытах: рядовой (15 см), широкорядные (с междурядьями
30 и 45 см) с нормами высева: 300 тыс. шт/га, 450 тыс. шт/га и 600 тыс. шт/га.

В течение вегетации проводились фенологические наблюдения, определяли густоту всходов и сохранность растений к уборке. Перед уборкой анализировали показатели структуры урожая на опытных растениях. Учет урожайности проводили поделяночно сплошным способом. Статистическая обработка полученных результатов проводилась по методике Б.А. Доспехова [10].

\section{Результаты исследования и их обсуждение}

Каждый сорт проявляет максимальную продуктивность при определенной площади питания растений. Способы и нормы высева семян влияют на густоту стояния растений, которая в свою очередь зависит от полевой всхожести семян и сохранности растений к уборке.

В наших исследованиях наблюдалось различие в показателях полевой всхожести и сохранности растений по годам опыта. Во всех вариантах в 2018 г. эти показатели были значительно ниже, чем в 2019 г. Это связываем в первую очередь с погодными условиями, так как в 2018 г. низкие температуры и недостаток влаги повлияли на полевую всхожесть семян сои. Сохранность растений к уборке также оказалась несколько ниже, видимо, из-за заморозков, наблюдавшихся в первой декаде июня.

Было установлено, что с увеличением нормы высева показатели полевой всхожести и сохранности растений к уборке увеличиваются в оба года исследований при рядовом способе посева. Так, в 2018 г. наивысшую полевую всхожесть имели варианты с нормами высева 600 тыс. шт/га при всех способах посева $(50,0-55,0 \%)$. В 2019 г. данная закономерность наблюдалась только при рядовом посеве, а в широкорядных посевах, наоборот, с увеличением нормы высева - она уменьшалась. Больше сохранялось растений к уборке в загущенных посевах. Так, в оба года опытов максимальная сохранность наблюдалась при норме высева 600 тыс. шт/га и составила от 90,0 до 96,7\%. Способы посева также оказали влияние на данный показатель. По годам исследований сохранность растений оказалась выше при посеве с междурядьями 45 см при всех нормах высева от 90,3 до $93,4 \%$ в 2018 г. до $94,2-98,3 \%$ в 2019 г. (табл. 1). Большее количество растений на единице площади впоследствии повлияло на урожайность сои. 
Таблица 1

Полевая всхожесть и сохранность растений сои в зависимости от способов и норм высева, \%

\begin{tabular}{|c|c|c|c|c|c|}
\hline Способы посева & Нормы высе- & \multicolumn{2}{|c|}{ Полевая всхожесть, \% } & \multicolumn{2}{c|}{ Сохранность растений, \% } \\
\cline { 2 - 5 } & ва, тыс. шт/га & 2018 г. & 2019 г. & 2018 г. & 2019 г. \\
\hline \multirow{3}{*}{ Рядовой (15 см) } & 300 & 46,7 & 75,0 & 85,7 & 91,5 \\
\cline { 2 - 5 } & 450 & 51,1 & 76,7 & 91,3 & 92,3 \\
\cline { 2 - 5 } & 600 & 53,3 & 83,3 & 90,6 & 96,7 \\
\hline \multirow{2}{*}{$\begin{array}{c}\text { Широкорядный } \\
\text { (30 см) }\end{array}$} & 300 & 48,3 & 86,7 & 89,7 & 87,3 \\
\cline { 2 - 5 } & 450 & 49,2 & 85,5 & 88,1 & 94,5 \\
\hline \multirow{2}{*}{$\begin{array}{c}\text { Широкорядный } \\
(45 \text { см) }\end{array}$} & 600 & 50,0 & 82,2 & 90,0 & 96,2 \\
\cline { 2 - 5 } & 300 & 53,3 & 88,3 & 90,3 & 94,2 \\
\cline { 2 - 5 } & 450 & 55,0 & 78,9 & 92,9 & 98,3 \\
\hline
\end{tabular}

В полевых условиях всходы сои появились в 2018 г. на 10-11-й день, в 2019 г. на 13-14-й день после посева. До начала цветения развитие растений в разных вариантах происходило одинаково. Затем, в более загущенных посевах, процесс плодообразования и созревания происходил медленнее. Продолжительность вегетационного периода в 2018 г. составила 91 день при нормах высева 450 и 300 тыс. на га и 98 дней при посеве с нормой высева 600 тыс. на га. В 2019 г. период вегетации затянулся и составил 124-132 дня, сохраняя закономерность предыдущего года.

Биометрический анализ растений сои показал, что более высокорослые растения сформировались при посеве семян с нормой 600 тыс. шт/га при широкорядном посеве 56,6 см, в этом варианте первый боб образовывался ниже на высоте 9,46 см от корневой шейки растения. В 2019 г. растения оказались более высокорослыми, что объясняется большим количеством осадков в течение вегетации. При норме высева 600 тыс. шт/га и ширине междурядий 45 см высота растений составила 73,8 см. Количество ветвей на растениях закономерно уменьшается с увеличением нормы высева, а высота образования первого боба увеличивается.

В 2018 г. показатели продуктивности растений, за исключением массы 1000 семян, оказались выше, чем в 2019 г. В среднем за два года при посеве рядовым способом наилучшие показатели продуктивности были получены при посеве с нормой высева 300 тыс. шт/га: количество бобов на растении - 41 шт., масса 1000 семян - 168,3 г. Эта же норма высева оказалась оптимальной и на широкорядных посевах. Было отмечено, что ширина междурядий при широкорядном посеве не оказала влияния на количество бобов с растения, количество семян в бобе и массу семян с растения при всех нормах высева. Наблюдались различия только по массе 1000 семян. Так, норма высева обеспечила ее максимальные показатели при всех способах посева (162,1-168,3 г), менее крупные семена образовались в вариантах с нормой высева 600 тыс. шт/га (153,5-157,8 г). Наибольший выход семян обеспечила норма высева 300 тыс. шт/га, в среднем с растения было получено 66-77 штук (табл. 2). Полученные результаты указывают на то, что для получения выполненных семян при различных способах посева следует сою высевать с нормой высева 300 тыс. шт/га. Анализируя широкорядные способы, отметили, что лучшие показатели продуктивности растений сои были получены при посеве с междурядьями 45 см.

Об эффективности применяемых приемов можно судить по урожайности культуры. Выбор оптимальных параметров посева должен свидетельствовать о достоверной прибавке урожая.

В табл. 3 представлены данные по урожайности при различных способах и нормах высева. Анализируя урожайность по годам исследований, можно констатировать, что 2019 г. оказался более благоприятным и продуктивным. При всех способах посева наблюдалось увеличение урожайности. В 2018 г. самым продуктивным оказался вариант с посевом с междурядьями 45 см и нормой высева 600 тыс. шт/га - 3,32 т/га, что достоверно превысило все другие варианты. Данная норма высева оказалась самой оптимальной при всех способах посева, меньшая урожайность была получена при норме высева 300 тыс. шт/га. Норма высева 600 тыс. шт/га при посеве с междурядьями 15 и 30 см показала практически одинаковые результаты. 
Продуктивность растений сои в зависимости от способов

Таблица 2 и норм высева (среднее за 2018-2019 гг.)

\begin{tabular}{|c|c|c|c|c|c|}
\hline Способы посева & Нормы высева, & \multicolumn{2}{|c|}{ Количество на растении, шт. } & \multicolumn{2}{|c|}{ Масса, г } \\
\cline { 3 - 6 } & & $\begin{array}{c}\text { продуктивных } \\
\text { бобов }\end{array}$ & семян в бобе & $\begin{array}{c}\text { семян } \\
\text { с растения }\end{array}$ & 1000 семян \\
\hline \multirow{3}{*}{ Рядовой (15 см) } & 300 & 41,0 & 1,88 & 13,0 & 168,3 \\
\cline { 2 - 6 } & 450 & 33,0 & 1,79 & 9,5 & 162,2 \\
\cline { 2 - 6 } & 600 & 32,7 & 1,76 & 8,9 & 153,5 \\
\hline \multirow{3}{*}{ Широкорядный (30 см) } & 300 & 35,6 & 1,86 & 10,7 & 162,1 \\
\cline { 2 - 6 } & 450 & 31,8 & 1,82 & 9,3 & 159,9 \\
\hline \multirow{3}{*}{ Широкорядный (45 см) } & 600 & 33,2 & 1,82 & 9,5 & 157,4 \\
\cline { 2 - 6 } & 300 & 35,2 & 1,87 & 10,9 & 166,1 \\
\cline { 2 - 6 } & 450 & 31,3 & 1,83 & 9,2 & 161,9 \\
\hline
\end{tabular}

Влияние способов и норм высева на урожайность сои

Таблица 3

\begin{tabular}{|c|c|c|c|}
\hline \multirow{2}{*}{$\begin{array}{l}\text { Способы посева } \\
\text { (фактор А) }\end{array}$} & \multirow{2}{*}{$\begin{array}{c}\text { Нормы высева, тыс. шт/га } \\
\text { (фактор В) }\end{array}$} & \multicolumn{2}{|c|}{ Урожайность, т/га } \\
\hline & & 2018 & 2019 \\
\hline \multirow{3}{*}{ Рядовой (15 см) } & 300 & 1,44 & 2,61 \\
\hline & 450 & 2,24 & 2,67 \\
\hline & 600 & 2,91 & 3,72 \\
\hline \multirow{3}{*}{ Широкорядный (30 см) } & 300 & 1,58 & 2,08 \\
\hline & 450 & 2,16 & 2,67 \\
\hline & 600 & 2,87 & 3,92 \\
\hline \multirow{3}{*}{ Широкорядный (45 см) } & 300 & 1,72 & 2,45 \\
\hline & 450 & 2,47 & 2,66 \\
\hline & 600 & 3,32 & 3,14 \\
\hline \multirow{3}{*}{$\mathrm{HPC}_{05}$} & по фактору А, т/га & 0,051 & 0,024 \\
\hline & по фактору В, т/га & 0,059 & 0,028 \\
\hline & по факторам AB, т/га & 0,052 & 0,050 \\
\hline
\end{tabular}

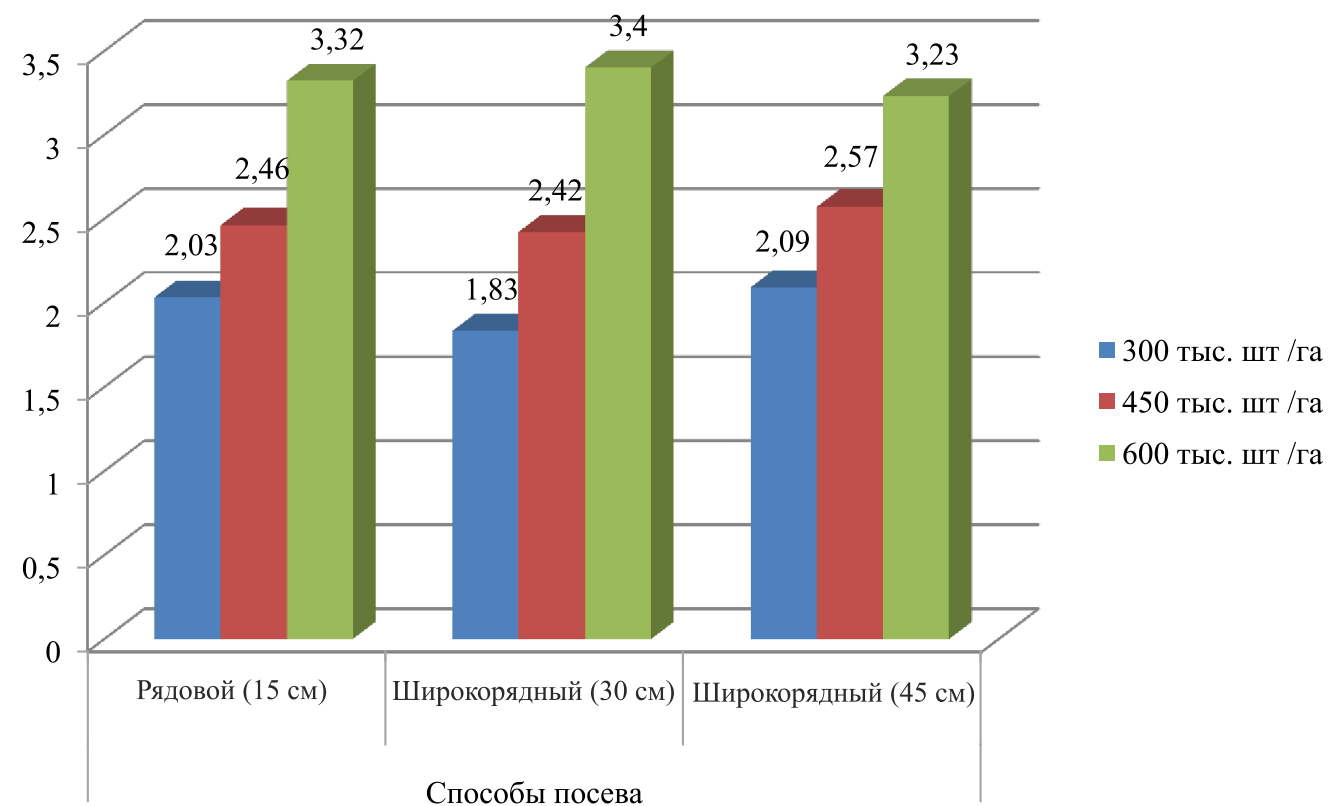

Зависимость урожайности сои от способов и норм высева, m/га (среднее за 2018-2019 гг.) 
В 2019 г. наибольшую урожайность обеспечил вариант с междурядьями $30 \mathrm{~cm}$ и нормой высева 600 тыс. шт/га - 3,92 т/га. При посеве с нормой 450 тыс. шт/га различий между рядовым и широкорядными (30 и 45 см) не наблюдалось $-2,66$ и 2,67 т/га. При посеве рядовым способом различия между нормами высева 300 тыс. шт/га и 450 тыс. шт/га не наблюдалось.

Несколько больше было влияние такого фактора, как норма высева, нежели способа посева. В 2019 г. взаимодействие обоих факторов (способа посева и нормы высева) оказалось сильнее, чем в 2018 г.

В среднем за два года с увеличением нормы высева происходило увеличение урожайности при всех способах посева. Наименьшие различия между способами посева наблюдались при посеве с нормой высева 450 тыс. шт/га (рисунок).

Полученная урожайность свидетельствует о том, что климатические и почвенные условия Чувашской Республики позволяют сформировать достаточные урожаи сои.

\section{Выводы}

В результате проведенных исследований было установлено, что оптимальный стеблестой сои на светло-серых лесных почвах Чувашской Республики формируется при посеве с нормой высева 600 тыс. шт/га как при рядовом, так и при широкорядном способах посева, что обеспечивает наибольшую урожайность сои. Однако для получения максимального количества выполненных семян с растения при различных способах посева следует сою высевать с нормой высева 300 тыс. шт/ га, что позволит увеличить коэффициент размножения.

\section{Список литературы / References}

1. Кривошлыков К.М., Рощина Е.Ю. Современные тенденции рынка сои в мире и России // Масличные культуры. Научно-технический бюллетень ВНИИМК. 2016. Вып. 2 (166). C. 68-72.

Krivoshlykov K.M., Roschina E.Yu. Modern trends in the soybean market in the world and Russia // Maslichnyye kul'tury. Nauchno-tekhnicheskiy byulleten' VNIIMK. 2016. Issue 2 (166). P. 68-72 (in Russian).

2. Баранов В.Ф., Уго Торо Корреа. Сортовая агротехника - резерв роста продуктивности сои // Земледелие. 2005. № 4. C. 42-43.

Baranov V.F., Ugo Toro Correa. Varietal agrotechnicsreserve of soy productivity growth // Zemledeliye. 2005. № 4. P. 42-43 (in Russian).

3. Елисеева Л.В., Кокуркина О.Т., Мефодьев Г.А. Изучение разнокачественности семян // Современные проблемы науки и образования. 2015. № 2-1. [Электрон- ный pecypc]. URL: https://science-education.ru/ru/article/ view?id=19154 (дата обращения: 17.04.2020).

Eliseeva L.V., Kokurkina O.T., Methodev G.A. Study of the heterogeneity of soybean seeds // Modern problems of science and education. 2015. № 2-1. [Electronic resource]. URL: https://science-education.ru/ru/article/view?id=19154 (date of access: 17.04.2020) (in Russian).

4. Ложкин А.Г. Изучение влияния элементов технологии возделывания сои сорта Чера 1 на качество семенного материала // Вестник Чувашской государственной сельскохозяйственной академии. 2017. № 1 (1). C. 14-17.

Lozhkin A.G. Study of the influence of elements of the technology of cultivation of soybean varieties Chera 1 on the quality of seed material // Bulletin of the Chuvash state agricultural Academy. 2017. № 1 (1). P. 14-17 (in Russian).

5. Казаченко И.Г., Адиньяев Э.Д., Абаев А.А., Хохоева Н.Т. Оптимальные нормы высева и способы посева перспективных сортов сои в условиях лесостепной зоны РСОАлания // Аграрный вестник Урала. 2011. № 3 (82). С. 6-7.

Kazachenko I.G., Adinev E.D., Abaev A.A., Khokhleva N.T. Optimal seeding rates and seeding opportunities for promising soybean varieties in the conditions of the foreststeppe zone of the RSO-Alania // Agrarian Bulletin of the Urals. 2011. № 3 (82). P. 6-7 (in Russian).

6. Хадарова И.В., Васильева Т.И., Елисеева Л.В. Изучение способов посева сои в УНПЦ «Студенческий» Чувашской ГСХА // Молодежь и инновации: материалы XIV Bceроссийской научно-практической конференции молодых ученых, аспирантов и студентов (г. Чебоксары, 21-22 марта 2018 г.). Чебоксары: Изд. Чувашская ГСХА, 2018. С. 74-76.

Hagarova I.V., Vasil'eva T.I., Eliseeva L.V. Studying of methods of sowing of soybean in ESPC «Student» Chuvash state agricultural Academy // Molodezh' i innovatsii: materialy XIV Vserossiyskoy nauchno-prakticheskoy konferentsii molodykh uchenykh, aspirantov i studentov (g. Cheboksary, 21-22 marta 2018 g.). Cheboksary: Izd. Chuvashskaya GSKHA, 2018. P. 74-76 (in Russian).

7. Каюкова О.В., Елисеева Л.В., Елисеев И.П. Реакция сортов сои на способы посева // Вестник Чувашской государственной сельскохозяйственной академии. 2019. № 1 (8). C. 31-35. DOI: $10.17022 /$ xaq6-5949.

Kayukova O.V., Eliseeva L.V., Eliseev I.P. Reaction of soybean varieties to seeding methods // Bulletin of the Chuvash State Agricultural Academy. 2019. № 1 (8). P. 31-35 (in Russian).

8. Митанова Н.Б., Пешкова А.А., Поморцев А.В., Дорофеев В.Н. Оптимизация нормы высева семян сои для выращивания её в лесостепи Иркутской области // Масличные культуры. Научно-технический бюллетень ВНИИМК. 2014. Вып. 1 (157-158). C. 69-73.

Mitanova N.B., Peshkova A.A., Pomortsev A.V., Dorofeev V.N. The determination of optimal seeding rate of soybean for its cultivation in the forest-steppe of the Irkutsk region // Maslichnyye kul'tury. Nauchno-tekhnicheskiy byulleten' VNIIMK. 2014. Issue 1 (157-158). P. 69-73 (in Russian).

9. Ваулин А.Ю. Способы посева и нормы высева сои на Южном Урале // Вестник Алтайского государственного аграрного университета. 2013. № 1 (99). С. 5-8.

Vaulin A.Yu. Soybean Planting Techniques And Rates in the Southern Urals // Bulletin of the Altai state agrarian University. 2013. № 1 (99). P. 5-8 (in Russian).

10. Доспехов Б.А. Методика полевого опыта: (с основами статистической обработки результатов исследований): учебник для студентов высших сельскохозяйственных учебных заведений по агрономическим специальностям. Изд. 6-е, стер., перепеч. с 5-го изд. 1985 г. М.: Альянс, 2011. 350 с.

Dospekhov B.A. Method of field experience: (with the basics of statistical processing of research results): textbook for students of higher agricultural educational institutions in agronomic specialties. Izd. 6-ye, ster., perepech. s 5-go izd. 1985 g. M.: Al'yans, 2011. 350 p. (in Russian). 